J. Med. Microbiol. — Vol. 46 (1997), 307-313

(C) 1997 The Pathological Society of Great Britain and Ireland

\title{
A three-way ribotyping scheme for Salmonella serotype Typhimurium and its usefulness for phylogenetic and epidemiological purposes
}

\author{
BEATRIZ GUERRA, ELENA LANDERAS, M. ANGELES GONZALEZ-HEVIA* and \\ M. CARMEN MENDOZA \\ Departamento de Biología Funcional, Area Microbiologia, Universidad de Oviedo, 33206 Oviedo and \\ * Laboratorio de Salud Pública, Principado de Asturias, Oviedo, Spain
}

\begin{abstract}
Ribotyping of Salmonella serotype Typhimurium strains was optimised as a tool for epidemiological and phylogenetic purposes. Of five restriction endonucleases evaluated on a series of 84 isolates, HincII, SaII and PvuII were the most useful, generating 13, 9 and 9 ribotypes with 17,11 and 18 polymorphic restriction sites, and attaining a discrimination index (DI) of $0.81,0.53$ and 0.59 , respectively. The combination of results from tests with the three enzymes provided further discrimination (19 ribotypes, $D I=0.84)$. It proved useful for clonal analysis, defining 19 clonal lines with a remarkable degree of genetic heterogeneity, that were grouped into two major clusters (including 12 and 7 lines, respectively) at a significance level of 0.65 . When the attributes of this system were compared with those of phage typing, it was found that ribotyping showed higher typability and sensitivity, supporting its use as an appropriate molecular method. In tracing the molecular epidemiology of Typhimurium strains in Asturias, six lines were found that could be considered endemic and were represented by organisms implicated in salmonellosis throughout the period of study; another four lines included organisms isolated from meat, water or both.
\end{abstract}

\section{Introduction}

Salmonella enterica serotype Typhimurium ( $S$. typhimurium) is associated with a wide variety of clinical manifestations [1], characterised by a wide dissemination among human and non-human sources; it is an important cause of food-borne infection in developed countries [2]. At the Spanish Reference Laboratory of Salmonella and Shigella, Typhimurium is second only to Enteritidis but its frequency has increased over the last few years, from 353 strains $(13 \%$ of serotyped salmonellas) in 1988 to $1160(25.1 \%)$ in 1994 ; it is also isolated more frequently than Enteritidis from nonavian meats [3, 4]. At the Principality of Asturias Public Health Laboratory (APHL, acting as Salmonella Asturian Reference Centre since 1990), during the period 1990-94, a total of 496 Typhimurium isolates (26\% of salmonellas serotyped) was processed, associated with 469 human sporadic episodes and six outbreaks.

Received 15 March 1996; revised version accepted 9 Sept. 1996.

Corresponding author: Professor M. C. Mendoza.
Epidemic strains of Typhimurium have been traced mainly by phage typing, although other phenotypic and molecular methods have provided useful epidemiological markers [5-10], including ribotyping by the analysis of restriction fragment length polymorphisms for highly conserved rRNA genes and associated sequences (rDNA region) [11, 12]. In the present study, an optimisation of the ribotyping procedure was attempted by the evaluation of five restriction endonucleases (REs) on a series of Typhimurium strains. A three-way ribotyping scheme (with HincII, $S a l \mathrm{I}$ and $P v u \mathrm{II})$ is proposed as a molecular method, and its value was tested both in terms of application to phylogenetics and the epidemiological surveillance of serotype Typhimurium.

\section{Materials and methods}

Bacterial strains and plasmids

This study included 84 isolates of Typhimurium from the collection of the APHL selected according to their date of isolation, place (in Asturian Health Area) of isolation, source and clinical and epidemiological presentation. The 72 human isolates included: 42 from 
Table 1. Sources and properties of Typhimurium strains used in this study

\begin{tabular}{|c|c|c|c|c|c|c|c|c|}
\hline \multirow{2}{*}{$\begin{array}{l}\text { Strain } \\
\text { ref. } \\
\text { no. }\end{array}$} & \multirow[b]{2}{*}{ Year } & \multirow{2}{*}{$\begin{array}{c}\text { Health } \\
\text { area }\end{array}$} & \multirow[b]{2}{*}{ Source } & \multirow{2}{*}{$\begin{array}{l}\text { Antigenic } \\
\text { formula }\end{array}$} & \multirow{2}{*}{$\begin{array}{l}\text { Phage } \\
\text { type }\end{array}$} & \multicolumn{3}{|c|}{ Ribotype with } \\
\hline & & & & & & $H i n \mathrm{clI}$ & SalI & $P v u \mathrm{II}$ \\
\hline 81 & 1987 & III & Faeces & 4,12 :i: 1,2 & 104 & $\mathrm{H} 1$ & $\mathrm{~S} 1$ & $\mathrm{P} 1$ \\
\hline 125 & 1987 & III & Faeces & 4,12 :i: 1,2 & $\ldots$ & $\mathrm{H} 1$ & $\mathrm{~S} 1$ & P1 \\
\hline 445 & 1988 & III & Faeces & 4,12 :i: 1,2 & UT & $\mathrm{H} 1$ & $\mathrm{~S} 1$ & $\mathrm{Pl}$ \\
\hline $515(2)$ & 1991 & IV & Faeces $\dagger$ & 4,12 :i: 1,2 & 104 & $\mathrm{H} 1$ & $\mathrm{~S} 1$ & $\mathrm{Pl}$ \\
\hline $828(2)$ & 1991 & IV & Drinking water & $4,5,12: \mathrm{i}: 1,2$ & 104 & $\mathrm{Hl}$ & $\mathrm{S} 1$ & $\mathrm{Pl}$ \\
\hline 14 & 1992 & IV & Faeces & 4,12 :i: 1,2 & 104 & $\mathrm{H} 1$ & S1 & $\mathrm{Pl}$ \\
\hline 15 & 1992 & IV & Faeces & 4,12 :i: 1,2 & 104 & $\mathrm{H1}$ & $\mathrm{S} 1$ & $\mathrm{Pl}$ \\
\hline 16 & 1992 & III & Faeces & 4,12 :i: 1,2 & 104 & $\mathrm{H} 1$ & $\mathrm{~S} 1$ & $\mathrm{Pl}$ \\
\hline 27 & 1992 & IV & Faeces & 4,12 :i: 1,2 & 104 & $\mathrm{H} 1$ & $\mathrm{~S} 1$ & $\mathrm{Pl}$ \\
\hline 28 & 1992 & III & Faeces & $4,12: \mathrm{i}: 1,2$ & UT & $\mathrm{Hl}$ & S1 & P1 \\
\hline 36 & 1992 & III & Faeces & 4,12 :i: 1,2 & UT & $\mathrm{Hl}$ & S1 & P1 \\
\hline 24 & 1993 & V & Faeces & $4,5,12$ :i: 1,2 & UT & $\mathrm{H} 1$ & $\mathrm{~S} 1$ & $\mathrm{Pl}$ \\
\hline 37 & 1993 & IV & Faeces & $4,5,12$ :i: 1,2 & 104 & $\mathrm{H} 1$ & $\mathrm{~S} 1$ & $\mathrm{Pl}$ \\
\hline 57 & 1993 & IV & Faeces & 4,12 :i: 1,2 & UT & $\mathrm{H} 1$ & $\mathrm{~S} 1$ & $\mathrm{P} 1$ \\
\hline 59 & 1993 & IV & Urine & 4,12 :i: 1,2 & 104 & $\mathrm{H} 1$ & $\mathrm{~S} 1$ & P1 \\
\hline $75(2)$ & 1993 & $\mathrm{~V}$ & Faecest & 4,12 :i: 1,2 & UT & $\mathrm{Hl}$ & $\mathrm{S} 1$ & $\mathrm{Pl}$ \\
\hline 189 & 1993 & IV & Abscess & 4,12 :i: 1,2 & 104 & $\mathrm{H} 1$ & S1 & $\mathrm{P} 1$ \\
\hline $453(6)$ & 1993 & I & Pork meat/faeces $\dagger$ & 4,12 :i: 1,2 & UT & $\mathrm{H} 1$ & $\mathrm{~S} 1$ & P1 \\
\hline 23 & 1994 & IV & Sputum & 4,12 :i: 1,2 & UT & $\mathrm{Hl}$ & $\mathrm{S} 1$ & $\mathrm{P} 1$ \\
\hline 209 & 1994 & IV & Sputum & 4,12 :i: 1,2 & UT & $\mathrm{H} 1$ & $\mathrm{~S} 1$ & P1 \\
\hline 412 & 1994 & VIII & Water $\$$ & 4,12 :i: 1,2 & UT & $\mathrm{H} 1$ & S1 & $\mathrm{P} 1$ \\
\hline 514 & 1994 & VIII & Water: & 4,12 :i: 1,2 & 104 & $\mathrm{H1}$ & $\mathrm{S} 1$ & $\mathrm{P} 1$ \\
\hline 520 & 1994 & VIII & Water & 4,12 :i: 1,2 & 104 & $\mathrm{Hl}$ & $\mathrm{S} 1$ & $\mathrm{Pl}$ \\
\hline 537 & 1994 & VIII & Water & 4,12 :i: 1,2 & 104 & $\mathrm{HI}$ & Sl & $\mathrm{Pl}$ \\
\hline 104 & 1990 & IV & Faeces $\dagger$ & $4,5,12$ :i: 1,2 & 193 & $\mathrm{H} 2$ & $\mathrm{~S} 1$ & $\mathrm{P} 1$ \\
\hline 18 & 1992 & III & Faeces & $4,5,12$ :i: 1,2 & 193 & $\mathrm{H} 2$ & $\mathrm{~S} 1$ & $\mathrm{P} 1$ \\
\hline 404 & 1992 & III & Faeces & $4,5,12$ :i: 1,2 & 120 & $\mathrm{H} 2$ & $\mathrm{~S} 1$ & $\mathrm{Pl}$ \\
\hline 43 & 1993 & $\mathrm{~V}$ & Tracheal aspirate & $4,5,12$ :i: 1,2 & 193 & $\mathrm{H} 2$ & $\mathrm{~S} 1$ & P1 \\
\hline 91 & 1993 & III & Faeces & $4,5,12$ :i: 1,2 & 193 & $\mathrm{H} 2$ & $\mathrm{~S} 1$ & $\mathrm{Pl}$ \\
\hline 95 & 1993 & III & Faeces & $4,5,12$ :i: 1,2 & 193 & $\mathrm{H} 2$ & $\mathrm{~S} 1$ & P1 \\
\hline 97 & 1993 & III & Faeces & $4,5,12$ :i: 1,2 & 193 & $\mathrm{H} 2$ & $\mathrm{~S} 1$ & $\mathrm{P} 1$ \\
\hline 43 & 1994 & I & Faeces & 4,12 :i: 1,2 & 193 & $\mathrm{H} 2$ & $\mathrm{~S} 1$ & $\mathrm{P} 1$ \\
\hline 13 & 1992 & III & Faeces & $4,5,12: i: 1,2$ & 193 & $\mathrm{H} 2$ & $\mathrm{~S} 1$ & $\mathrm{P} 1$ \\
\hline 29 & 1992 & III & Faeces & $4,5,12$ :i: 1,2 & 193 & $\mathrm{H} 2$ & S1 & P1 \\
\hline 6 & 1993 & III & Faeces & $4,5,12$ :i: 1,2 & 193 & $\mathrm{H} 2$ & S1 & $\mathrm{P} 1$ \\
\hline 47 & 1992 & II & Faeces & $4,5,12$ :i: 1,2 & 104 & $\mathrm{H} 3$ & S1 & $\mathrm{P} 1$ \\
\hline 22 & 1992 & IV & Faeces & $4,12: \mathrm{i}: 1,2$ & UT & $\mathrm{H} 3$ & S1 & $\mathrm{P} 2$ \\
\hline 363 & 1991 & III & Pus & $4,5,12: 1: 1,2$ & 195 & $\mathrm{H} 3$ & $\mathrm{~S} 2$ & $\mathrm{P} 2$ \\
\hline 365 & 1991 & III & Urine & $4,5,12$ :i: 1,2 & 195 & $\mathrm{H} 3$ & $\mathrm{~S} 2$ & $\mathrm{P} 2$ \\
\hline 31 & 1993 & V & Faeces & $4,5,12$ :i: 1,2 & 104 & $\mathrm{H} 3$ & $\mathrm{~S} 2$ & $\mathrm{P} 2$ \\
\hline 179 & 1993 & IV & Faeces & $4,5,12: \mathrm{i}: 1,2$ & 193 & $\mathrm{H} 3$ & $\mathrm{~S} 2$ & $\mathrm{P} 2$ \\
\hline 106 & 1994 & V & Faeces & 4,12 :i: 1,2 & UT & H3 & $\mathrm{S} 2$ & $\mathrm{P} 2$ \\
\hline 57 & 1985 & III & Faeces & $4,5,12$ :i: 1,2 & 66 & $\mathrm{H} 3$ & $\mathrm{~S} 2$ & $\mathrm{P} 2$ \\
\hline 34 & 1994 & V & Faeces & 4,12 :i: 1,2 & 5 & $\mathrm{H} 3$ & $\mathrm{~S} 2$ & P8 \\
\hline 298 & 1988 & III & Bile & $4,5,12$ :i: 1,2 & 204 & $\mathrm{H} 4$ & $\mathrm{~S} 1$ & $\mathrm{Pl}$ \\
\hline $346(3)$ & 1992 & IV & Faeces $\dagger$ & $4,5,12$ :i: 1,2 & UT & $\mathrm{H} 4$ & $\mathrm{~S} 1$ & P1 \\
\hline 392 & 1992 & IV & Lymphatic system & $4,5,12: \mathrm{i}: 1,2$ & UT & $\mathrm{H} 4$ & $\mathrm{~S} 1$ & $\mathrm{P} 1$ \\
\hline 13 & 1994 & II & Faeces & $4,5,12: \mathrm{i}: 1,2$ & 203 & $\mathrm{H} 4$ & $\mathrm{~S} 1$ & P1 \\
\hline 8 & 1993 & IV & Faeces & $4,5,12: \mathrm{i}: 1,2$ & UT & $\mathrm{H} 4$ & $\mathrm{~S} 1$ & $\mathrm{P} 1$ \\
\hline 722 & 1992 & IV & Urine & $4,5,12$ :i: 1,2 & 80 & $\mathrm{H} 4$ & $\mathrm{~S} 1$ & P1 \\
\hline 166 & 1994 & III & Faeces & 4,12 :i: 1,2 & 80 & $\mathrm{H} 4$ & $\mathrm{~S} 1$ & $\mathrm{Pl}$ \\
\hline 139 & 1987 & III & Faeces & 4,12 :i: 1,2 & 96 & $\mathrm{H} 4$ & $\mathrm{~S} 1$ & $\mathrm{P} 4$ \\
\hline 415 & 1988 & III & Faeces & $4,5,12: i: 1,2$ & 96 & $\mathrm{H} 4$ & $\mathrm{~S} 1$ & $\mathrm{P} 4$ \\
\hline $122(7)$ & 1994 & III & Faeces $\dagger$ & 4,12 :i: 1,2 & 96 & $\mathrm{H} 4$ & $\mathrm{~S} 1$ & $\mathrm{P} 4$ \\
\hline 14 & 1993 & IV & Faeces & $4,5,12$ :i: 1,2 & 104 & $\mathrm{H} 4$ & $\mathrm{~S} 2$ & $\mathrm{P} 2$ \\
\hline 56 & 1984 & III & Faeces & 4,12 :i: 1,2 & UT & H5 & S3 & P3 \\
\hline 674 & 1991 & IV & Blood & $4,5,12$ :i: 1,2 & UT & H5 & S3 & P3 \\
\hline 80 & 1993 & II & Faeces & $4,5,12$ :i: 1,2 & 193 & H5 & S3 & P3 \\
\hline 150 & 1994 & IV & Faeces & $4,12: \mathrm{i}: 1,2$ & 23 & H5 & S3 & P3 \\
\hline 323 & 1994 & II & Blood & 4,12 :i: 1,2 & 23 & H5 & S3 & P3 \\
\hline 23 & 1984 & III & Faeces & 4,12 :i: 1,2 & UT & H6 & S4 & P5 \\
\hline 100 & 1984 & III & Faeces & 4,12 :i: 1,2 & UT & H6 & $\mathrm{S} 4$ & P5 \\
\hline 72 & 1986 & III & Faeces & $4,5,12$ :i: 1,2 & 124 & $\mathrm{H} 7$ & S3 & P6 \\
\hline 611 & 1991 & II & Drinking water & $4,5,12$ :i: 1,2 & 28 & $\mathrm{H} 7$ & S3 & P6 \\
\hline 502 & 1994 & VII & Water $\ddagger$ & 4,12 :i: 1,2 & UT & $\mathrm{H} 8$ & $\mathrm{~S} 2$ & $\mathrm{P} 2$ \\
\hline 15 & 1985 & III & Faeces & 4,12 :i: 1,2 & $\ldots$ & $\mathrm{H} 9$ & S6 & $\mathrm{P} 4$ \\
\hline 443 & 1994 & VIII & Waterf & 4,12 :i: 1,2 & 193 & $\mathrm{H} 10$ & S5 & P7 \\
\hline 94 & 1993 & IV & Faeces & $4,5,12: \mathrm{i}: 1,2$ & 193 & $\mathrm{H} 11$ & S7 & $\mathrm{Pl}$ \\
\hline Reference & ins & & & & & & & \\
\hline 247 & 1994 & Spain & Blood & 4,12 :i: 1,2 & $\cdots$ & $\mathrm{H} 1$ & S1 & $\mathrm{P} 1$ \\
\hline BC-LT2 & $\ldots$ & Germany & & 4,12 :i: 1,2 & $\cdots$ & $\mathrm{H} 3$ & S8 & $\mathrm{P} 2$ \\
\hline ATCC & $\cdots$ & USA & & 4,12 :i: 1,2 & $\ldots$ & H12 & S9 & P9 \\
\hline 14028 & & & & & & & & \\
\hline BC-25268 & 1975 & Germany & & 4,12 :i: 1,2 & $\cdots$ & $\mathrm{H} 13$ & S3 & P3 \\
\hline
\end{tabular}

Reference strains were from: BC, Bayer A.G., Research Centre, Wuppertal, Germany; ATCC American Type Culture Collection. Strains are listed in order according to their ribotypes (RTs) beginning with HincII. UT, phage untypable by the scheme of Anderson et al. [15]. ${ }^{*}$ Number of isolates tested (in parentheses) if $>1$.

†Outbreak.

†reated sewage water. 
sporadic episodes of acute enteritis; 12 from sporadic episodes of extra-intestinal infection; and 18 faecal isolates from six different food-borne outbreaks. All 72 isolates came from persons requiring treatment in Asturian Hospitals during the period 1984-94. In addition, there were three isolates from pork meat implicated in one of the outbreaks, three from drinking water and six from treated sewage water. Four Typhimurium strains from other collections were used as reference strains (Table 1); one strain (93/92) of Enteritidis belonging to the prevalent clonal line in the Principality of Asturias [13] was used as an outgroup strain.

Plasmid pKK3535, which carries the $r r n B$ operon from Escherichia coli cloned in the BamHI site of pBR322 [14], was used as the source of probe DNA. The probe was a $7.5-\mathrm{kb}$ Bam $\mathrm{HI}$ fragment labelled with 11-d-UDP-digoxigenin according to the instructions of the kit manufacturer (Boehringer-Mannheim).

\section{Serotyping and phage typing}

Serotyping of strains was performed by slide-agglutination tests with commercial somatic (O) and flagellar (H) antisera (Sanofi Diagnostic Pasteur, France) and they were confirmed as belonging to serotype Typhimurium $(4,[5], 12: i: 1,2)$. Phage typing, by the extended phage-typing scheme of Anderson et al. [15], was performed in the Spanish Reference Laboratory of Salmonella and Shigella, Instituto de Salud Carlos III, Majadahonda, Madrid.

\section{Ribotyping}

Chromosomal DNA was obtained and purified by an SDS-phenol isolation method [16]. Samples were cleaved with REs and tested by Southern blot hybridisation, performed as described previously [17, 18] with a non-radioactive DNA labelling and detection kit (Boehringer-Mannheim). In the analysis of each RE, isolates representing the different banding patterns were tested at least three times to evaluate the reproducibility of the method. The patterns of bands containing rRNA gene sequences were designated ribotypes. The polymorphic restriction sites (PRS) were deduced by the presence or absence of bands among the total ribotypes from each RE as described before [18, 19]. Strains showing identical ribotypes after testing with HincII, SalI and PvuII, were ascribed to the same clonal line.

\section{Statistical analysis}

The discrimination index (DI), the probability that two unrelated strains sampled from the population would be placed into different typing groups, was calculated by Simpson's index of diversity [20].

For phylogenetic analysis, the totality of the ribotypes generated with each of the enzymes HincII, SalI and $P v u$ II was first analysed; then the combined data from all three REs were processed as described earlier [18]. Thus, clustering analysis between combined ribotypes was carried out by Jaccard's distance coefficient (D) and the unweighted pair group method with arithmetic averages (UPGMA) in the software Programme MVSP (Multivariate Statistics Package, 2.0a).

\section{Results}

Value of five restriction endonucleases in ribotyping Typhimurium

A total of 84 Asturian isolates of Typhimurium and four reference strains was analysed by ribotyping. Total genomic DNA from each was separately cleaved with five REs: HincII, SalI, $P v u \mathrm{II}, E c o$ RI and $B g l \mathrm{I}$, and the different results in rDNA restriction patterns were observed for each. Data from the ribotyping of organisms associated with six outbreaks showed that, in all cases, the isolates from each outbreak yielded identical ribotypes with the five REs, allowing them to be considered as six different strains. Thus, the 84 Asturian Typhimurium isolates were grouped into 68 strains, as listed in Table 1. All strains could be typed, and with each RE one ribotype was clearly more frequent than the others. For the remaining stages of the present study, results with EcoRI and BglI were discarded, as they were not considered sufficient for meaningful discrimination or of value as a typing tool: EcoRI generated only three ribotypes (represented by 63,8 and 1 strains, respectively) and showed a very low discriminatory power; $B g l \mathrm{I}$ was discarded because it frequently generated partial digestions and its banding patterns were also difficult to interpret, due to the close situation of fragments in the region $3.5-$ $2.5 \mathrm{~kb}$.

With HincII, strains were discriminated into 13 ribotypes (labelled $\mathrm{H} 1-\mathrm{H} 13$ ) including 13-16 fragments of small size $(6.5-0.5 \mathrm{~kb})$. When the ribotypes were compared, six fragments common to all were found, and the analysis of the uncommon fragments led us to establish 17 PRS (Fig. 1). With SalI, nine ribotypes (S1-S9) were generated, with 11-15 fragments (sizes 23-2 kb), seven common fragments and 11 PRS (Fig. 2). With $P v u \mathrm{II}$, nine ribotypes (P1-P9) including 13-15 fragments (sizes $14.2-1.7 \mathrm{~kb}$ ), six common fragments, and 18 PRS were obtained (Fig. 3). The banding patterns yielded with each of the REs in Typhimurium strains were very similar to one another and, albeit with a lower number of common fragments, to Enteritidis ribotypes (Figs 1-3).

The Typhimurium strains, shown in Table 1, were used to evaluate the discriminatory power of the method with each of three chosen REs, by means of two parameters: number of ribotypes generated and calculation of a discrimination index (DI), which 


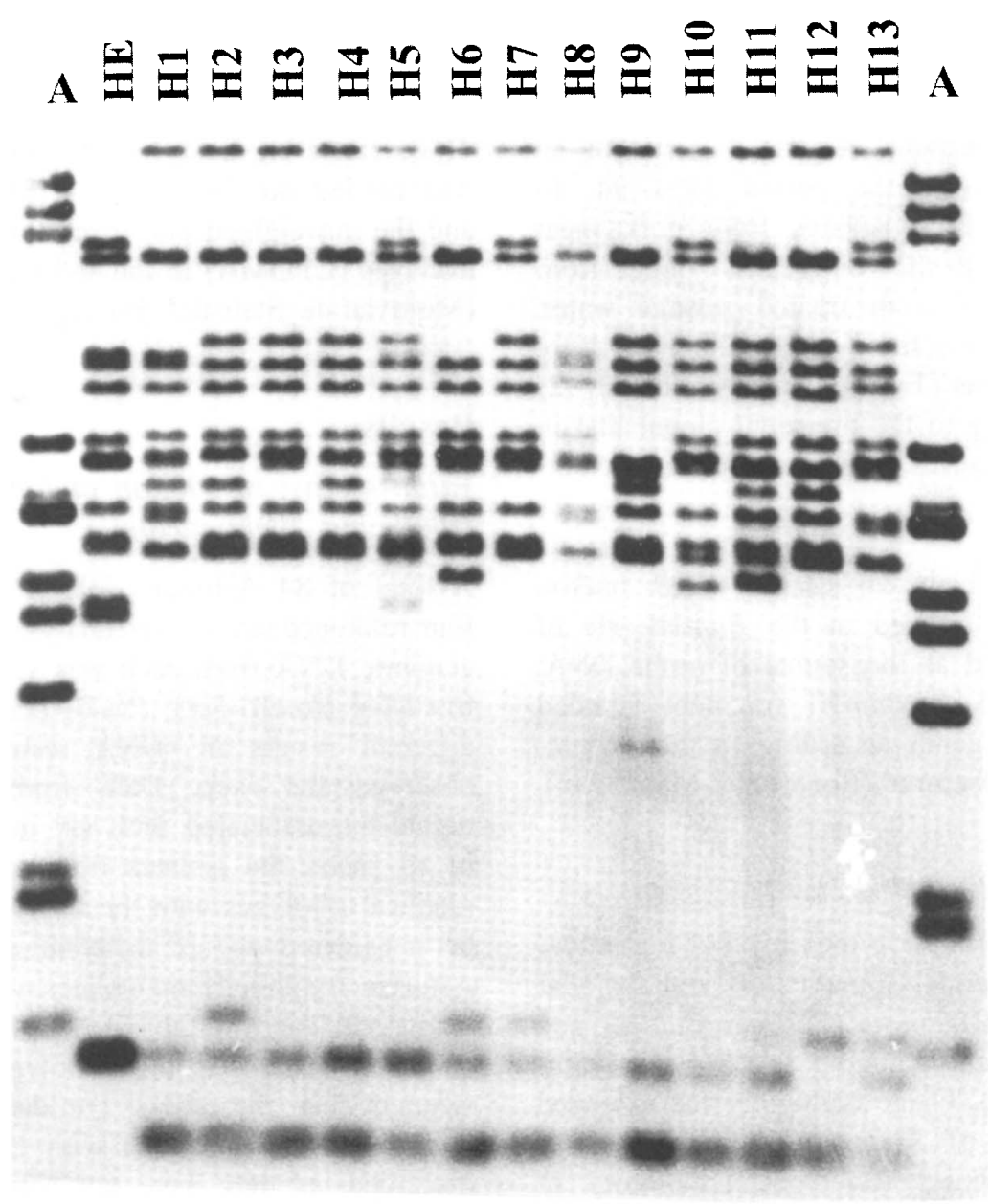

Fig. 1. Ribotypes generated by HincII in Typhimurium. Lane A, lambda DNA cleaved with Psi I; sizes of fragments (kb) from top to bottom are $5.08,4.65,4.5,2.84,2.58,2.44,2.14,1.98,1.70,1.16,1.09$, and 0.81 . HE, ribotype pattern of Enteritidis strain $93 / 92$.

takes into consideration both the number of types defined by the typing method and their relative frequencies. The DIs obtained were: 0.81 with HincII, 0.53 with SalI and 0.59 with $P v u$ II. The increase in discriminatory power by combination of data from two and three REs was also evaluated, resulting in a different distribution of strains; the number of combined ribotypes (CRTs) and DIs obtained with the combinations of REs were: HincII with $P v u$ II 17 CRTs, DI $=0.83$; HincII with SalI 16, 0.83; SalI with $P v u$ II 13, 0.61; and HincII with $P v u$ II and SalI, 19, 0.84. These data allowed us to propose and to evaluate as a molecular tool a three-way ribotyping scheme with HincII, SalI and $P v u$ II, because it yielded the highest discrimination. The 19 CRTs were considered as clonal lines (labelled I-XIX.). The distribution of strains into lines is also shown (Fig. 4). The most frequent was line I $(34.72 \%)$, represented by 24 Asturian strains and the reference strain labelled $247 / 94$, a clinical isolate that had caused septicaemia in a hospitalised patient from another Spanish city (Burgos). Fifteen lines (II-XVI) were represented by
Asturian strains only, the other three lines (XVIIXIX) by each of the other reference strains: Typhimurium LT2, ATCC 14028 and 25268, a highly virulent clinical isolate from Germany [21]. Enteritidis strain 93/92 was ascribed to line XX.

\section{Correlation between the three-way ribotyping scheme and phage typing}

The results obtained from the three-way ribotyping scheme were compared with phage-typing results [15]. Whereas all strains could be ribotyped, 20 (of 66) phage-typed strains were phage untypable (UT). Strains grouped in the two most frequent phage types were divided by ribotyping: 16 strains of PT104 into clonal lines I, III, V, IX and 14 strains of PT193 into clonal lines II, V, X, XV and XVI. Three strains of PT23 were ascribed to line $X$, and three strains of PT96 to line VIII. On the other hand, it is noteworthy that the most frequent line (I) included only strains of PT104 or that were UT; the second most frequent line (II) included strains of PTs 193 and 120 only. 

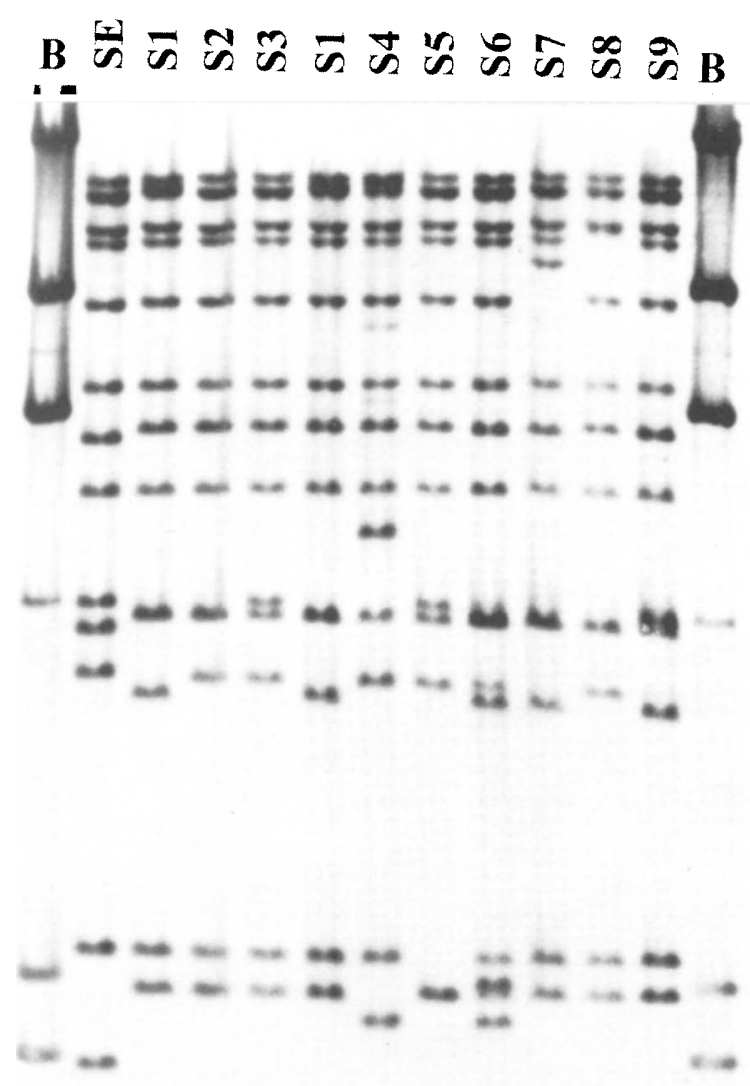

Fig. 2. Ribotypes generated by $S a l \mathrm{I}$ in Typhimurium. Lane B, lambda DNA cleaved with HindIII: sizes of fragments $(\mathrm{kb})$ from top to bottom are $23.13,9.42,6.56$, 4.36, 2.32 and 2.03. SE, ribotype pattern of Enteritidis strain $93 / 92$.

Clonal analysis of Typhimurium by the three-way ribotyping scheme

With the data from the analysis of the fragments generated by HincII, SalI and PvuII, an index of similarity between clonal lines was calculated and a dendrogram (Fig. 4) was constructed from the similarity matrix. The 19 clonal lines of Typhimurium showed genetic distance coefficients (D) between 0.16 and 0.64 and, at a significance level of 0.65 , they were grouped into two major clusters (labelled A and B) each with two subclusters. Cluster A grouped 12 lines and cluster $B$ grouped the other seven lines. All strains of Typhimurium appeared loosely related $(\mathrm{D}=0.78)$ to the out-group strain $93 / 92$ of Enteritidis.

\section{Discussion}

The evaluation of a typing system for epidemiological purposes should have established a series of attributes including: stability, typability, reproducibility, sensitivity or discriminatory power $[11,22]$. Three features of
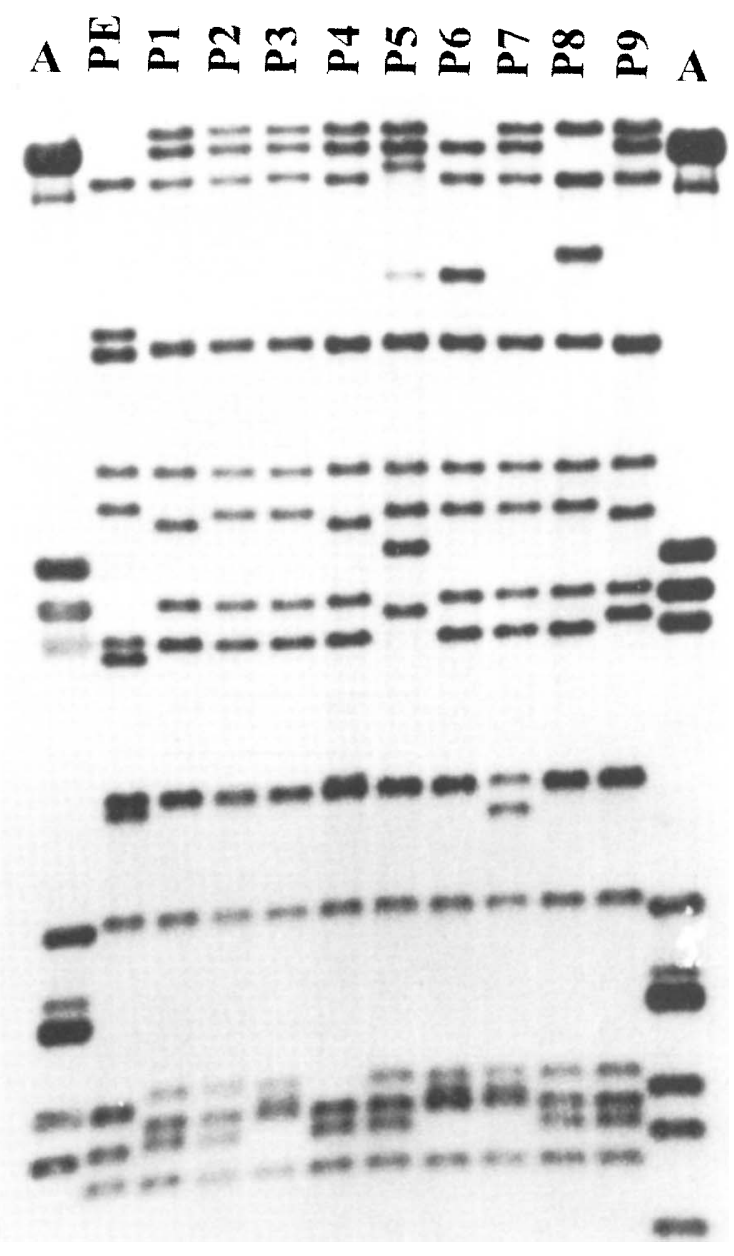

Fig. 3. Ribotypes generated by $P v u I I$ in Typhimurium. Lane A, lambda DNA cleaved with Pst I: sizes of fragments $(\mathrm{kb})$ from top to bottom are $14.17,11.51$, $5.08,4.65,4.5,2.84,2.58,2.44,2.14,1.98$ and 1.7. PE, ribotype pattern of Enteritidis strain $93 / 92$.

the three-way ribotyping scheme reached $100 \%$ (stability, typability and reproducibility). With respect to sensitivity, the series under study was differentiated into 19 groupings or clonal lines with a $\mathrm{DI}=0.84$, which is less than that (DI $>0.95$ ) proposed as optimum by Hunter and Gaston [20]; however, if the limited size of the present series and the limited geographic region from which it was collected are taken into account, a DI of 0.84 may be considered satisfactory.

Ribotyping may be considered the universal eubacterial genetic typing method, because it uses common probes as well as available equipment, reagents and supplies. However, for different Salmonella serotypes, different REs have been found to be most useful in producing interpretable ribotypes $[6,9,23,24]$ and the present study identified Hincll alone, or in combination with SalI and $P v u I I$, as the most useful RE in subtyping Typhimurium. HincIl ribotyping of 


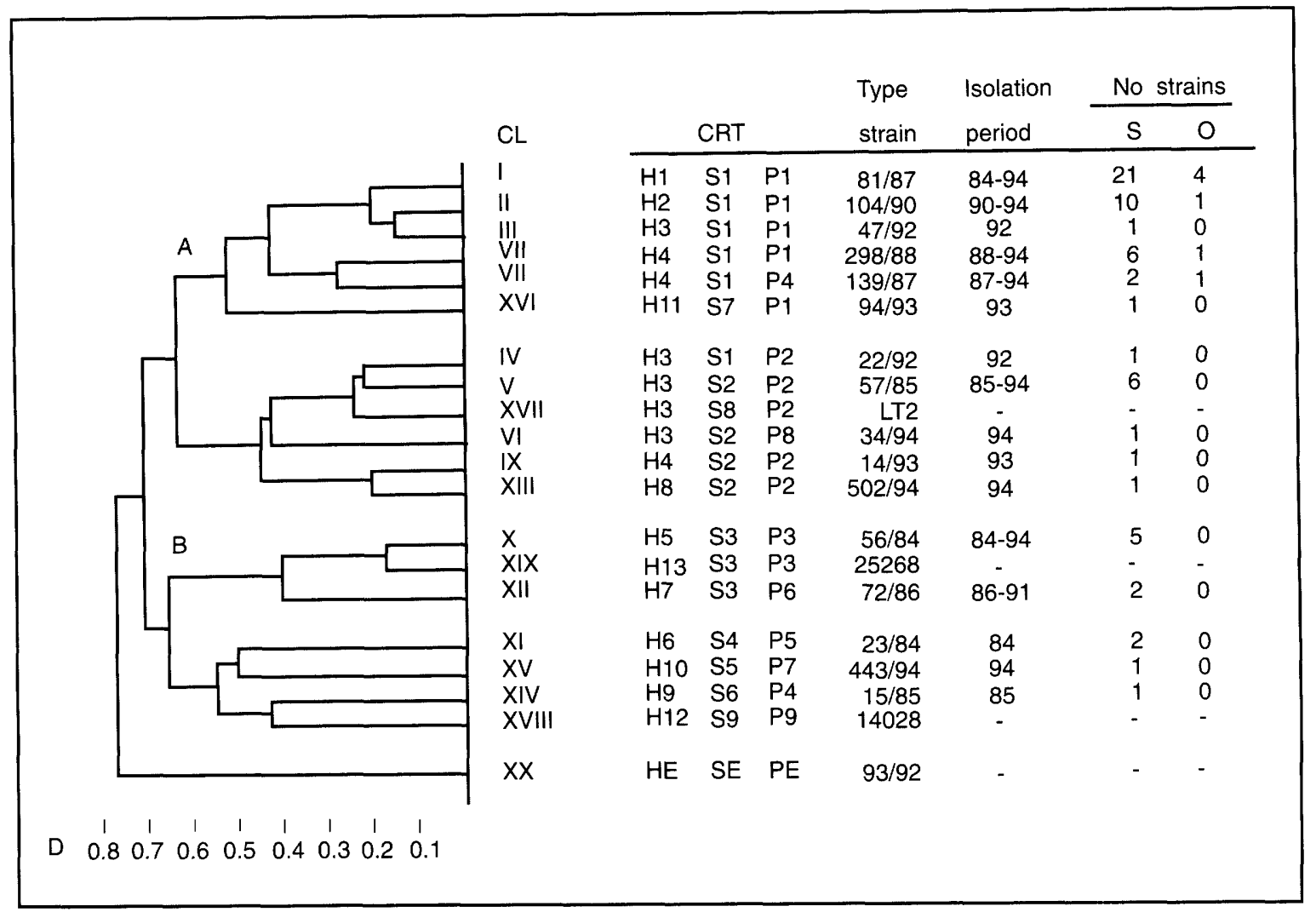

Fig. 4. Single linkage dendrogram showing the results of cluster analysis on the basis of HincII, SalI and $P v u$ II combined ribotypes of strains of Typhimurium. CL, clonal line; CRT, combined ribotype; D, genetic distance coefficient; S, sporadic; O, outbreak. The earliest strain showing the cited combined ribotype is given as the type strain. Major clusters, A and B, are shown at a significance level of 0.65 . Clonal line XX is Enteritidis strain $93 / 92$.

Typhimurium has been reported by Nastasi et al. [6]; when results from that and the present series were compared, ribotypes numbered $8,5,1-14,6,2$ and 16 found by Nastasi et al. [6] among Italian isolates seemed identical or very similar to ribotypes $\mathrm{H} 1, \mathrm{H} 3$, $\mathrm{H} 4, \mathrm{H} 7, \mathrm{H} 13$ and $\mathrm{H} 11$, respectively, among Asturian strains. It should be pointed out, however, that the rates of the most frequent ribotypes in the two series were different.

It is noteworthy that the three REs generated some very well differentiated uncommon fragments in the rDNA banding patterns and in some cases would enable the deduction of possible genetic changes undergone, and so appear to offer a good tool for phylogenetic analysis, which could be used together with other markers, as previously described $[7,9]$. It must also be emphasised that HincII recognised ambiguous DNA sequences $(\mathrm{GT}(\mathrm{T} / \mathrm{C}) \mid(\mathrm{A} / \mathrm{G}) \mathrm{AC})$ that included the Sal I recognition sequence (G/TCGAC) as a subsequence. This implies that the ribotypes generated with HincII include fragments of a smaller size than Sall-ribotypes and that the patterns from both REs are very different. The differences were also translated into the number of ribotypes and in the distribution of the strains generated by each RE.

A comparison between phage-typing and the three-way ribotyping scheme revealed a higher typability and sensitivity associated with the latter and also revealed some relationships. The most frequent clonal lines included only strains of the most frequent PTs or strains that were phage untypable. However, the most frequent PTs (104 and 193) could be differentiated into four and five lines, respectively. It should also be noted that three PT96 strains analysed (isolated in different years) were the only ones that were ascribed to line VIII. In this sense, all the data presented support ribotyping as both a complementary and alternative tool to phage typing for epidemiological studies.

Data from HincII, SalI and $P v u$ II ribotyping were used to elucidate the genetic relationships found among the clonal lines of Typhimurium, as well as for an approach to its molecular epidemiology in the Principality of Asturias, Spain. The results enabled the detection of genotypic differences that provided the differentiation of clinical organisms into 14 clonal lines showing a high degree of genetic heterogeneity. It should be noted that $59.71 \%$ of the Asturian strains belonged to the three most frequent lines (I, II and VII), which may be considered to be closely related and, differing only in their HincII ribotypes, fall into cluster A. Organisms ascribed to these lines may be considered as highly ubiquitous, because they were 
collected from clinical, food and water samples in different Asturian geographic areas, in different years and were associated with both sporadic episodes of salmonellosis and five outbreaks. Line I also included four strains isolated from treated sewage water, data supporting its capacity for survival in that environment. The fourth and fifth most frequent lines $(\mathrm{V}$ and $\mathrm{X}$ with 8.82 and $7.35 \%$ of Asturian strains, respectively), were represented only by organisms causing sporadic episodes of salmonellosis; line $\mathrm{V}$ belonged to cluster $\mathrm{A}$ and line $\mathrm{X}$ to cluster $\mathrm{B}$. Both lines were less related to each other, and to the three most frequent lines cited above, differing in the ribotypes generated with the three REs. The five lines cited, together with line VIII (4.41\% of Asturian strains) might be considered as endemic in Asturias, because they included organisms circulating and causing human salmonellosis throughout recent years. Organisms of other lines, which appeared at a low frequency, seem to play a less important role in human illness.

All these data suggest that the proposed three-way ribotyping scheme is a useful molecular technique which may be used for different epidemiological purposes: in epidemiological surveillance in both retrospective and prospective studies; in the diagnosis and surveillance of outbreaks; in studies of the evolution of clones through time and space; and in the surveillance of pathogenic clones in natural environments. It may also be useful at the level of the individual patient, for the diagnosis-surveillance of bacterial translocation, just as for the surveillance of excretion of bacteria from infected patients or healthy carriers.

We thank the following: Dr M. Altwegg for pKK3535 plasmid; Dr A Aladueña for serotyping and phage typing Typhimurium strains; Dr H-P. Kroll, Dr Wauters, Dra. C. Marne and ATCC for reference strains; and the Microbiology Laboratories of Hospital Central de Asturias, Oviedo, Hospital San Agustin, Avilés, Hospital de Cabueñes, Gijón Hospital Comarcal de Jarrio and Hospital Carmen and Severo Ochoa, Cangas del Narcea, for clinical isolates. This work was supported by grants from Oviedo University (no. 94/128-2) and Fondo de Investigación Sanitaria (no. 95/0030).

\section{References}

1. Golberg MB, Rubin RH. The spectrum of Salmonella infection. Infect Dis Clin North Am 1988; 2: 571-598.

2. Pang T, Bhutta ZA, Finlay BB, Altwegg M. Typhoid fever and other salmonellosis: a continuing challenge. Trends Microbiol 1995; 3: 253-255.

3. Echeitia MA, Usera MA. Prevalence of Salmonella serotypes isolated in Spain from human and non human sources (19831987). Microbiologia 1989; 5: 95-103.

4. Usera MA, Diez R, Echeitia A. Análisis de los serotipos de Salmonella $s p$ aislados en España en el año 1994. Boletín Epidemiológico Semanal 1995; 3: 165-172.
5. Threlfall EJ, Frost JA. The identification, typing and fingerprinting of Salmonella: laboratory aspects and epidemiological applications. J Appl Bacteriol 1990; 68: 15-16.

6. Nastasi A, Mammina C, Villafrate MR, Epidemiology of Salmonella typhimurium: ribosomal DNA analysis of strains from human and animal sources. Epidemiol Infect 1993; 110: $553-565$.

7. Stanley J, Baquar N, Threlfall EJ. Genotypes and phylogenetic relationships of Salmonella typhimurium are defined by molecular fingerprinting of IS:200 and 16s rrn loci. $J$ Gen Microbiol 1993; 139: 1133-1140.

8. Hampton MD, Threlfall EJ, Frost JA, Ward LR, Rowe B Salmonella typhimurium DT193: differentiation of an epidemic phage type by antibiogram, plasmid profile, plasmid fingerprint and Salmonella plasmid virulence (spv) gene probe. $J$ Appl Bacteriol 1995; 78: 402-408

9. Milleman Y, Lesage M-C, Chaslus-Dancla E, Lafont J-P. Value of plasmid profiling, ribotyping, and detection of IS200 for tracing avian isolates of Salmonella typhimurium and $S$ enteritidis. J Clin Microbiol 1995; 33: 173-179.

10. González-Hevia MA, Gutierrez MF, Mendoza MC. Diagnosis by combination of typing methods of a Salmonella typhimurium outbreak associated with cured-ham, an unusual infection source. J Food Protec 1996; 59: 426-429.

11. Pfaller MA. Typing methods for epidemiologic investigation. In: Balows A, Hausler WJ, Herrmann KL, Isenberg HD, Shadomy HJ (eds) Manual of clinical microbiology, 5th edn. Washington, D.C., American Society for Microbiology. 1991: $171-182$.

12. Stull TL, LiPuma JJ, Edlind TD. A broad-spectrum probe for molecular epidemiology of bacteria: ribosomal RNA. I Infect Dis 1988; 157: 280-286.

13. González-Hevia MA, Llaneza JJ, Mendoza MC. Usefuiness of molecular genetic markers in the typing of Salmonella enterica serovar Enteritidis causing a food-borne outbreak. Int J Food Microbiol 1994; 22: 97-103.

14. Brosius J, Ullrich A, Raker MA et al. Construction and fine mapping of recombinant plasmids containing the $r r n \mathrm{~B}$ ribosomal RNA operon of E. coli. Plasmid 1981; 6: 112-118.

15. Anderson ES, Ward LR, de Saxe MJ, de Sa JDH Bacteriophage-typing designations of Salmonella typhimurium. J Hyg 1977; 78: 297-300.

16. Mak YM, Ho KK. An improved method for the isolation of chromosomal DNA from various bacteria and cyanobacteria. Nucleic Acids Res 1992; 20: 4101-4102.

17. Sambrook J, Fritsch EF, Maniatis T. Molecular cloning: a laboratory manual, 2nd edn. Cold Spring Harbor, NY, Cold Spring Harbor Laboratory Press. 1989.

18. Mendoza MC, Alzugaray R, Landeras E, Gónzalez-Hevia MA Discriminatory power and application of ribotyping of Yersinia enterocolitica $\mathrm{O}: 3$ in an epidemiological study. Eur J Clin Microbiol Infect Dis 1996; 15: 220-226.

19. Karaolis DKR, Lan R, Reeves PR. Sequence variation in Shigella sonnei (Sonnei), a pathogenic clone of Escherichia coli, over four continents and 41 years. J Clin Microbiol 1994; 32: $796-802$.

20. Hunter PR, Gaston MA. Numerical index of the discriminatory ability of typing systems: an application of Simpson's index of diversity. J Clin Microbiol 1988; 26: 2465-2466.

21. Brunner H, Kroll HP. Reduced proliferative response of mouse spleen cells to mitogens during infection with Salmonella typhimurium or Listeria monocytogenes. Microb Pathog 1989; 6: $365-276$

22. Maslow JN, Mulligan ME, Arbeit RD. Molecular epidemiology: application of contemporary techniques to the typing of microorganisms. Clin Infect Dis 1993; 17: 153-64.

23. Esteban E, Snipes K, Hird D, Kasten R, Kinde H. Use of ribotyping for characterization of Salmonella serotypes. $J$ Clin Microbiol 1993; 31: 233-237.

24. Landeras E, Gonzalez-Hevia MA, Alzugaray R, Mendoza MC. Epidemiological differentiation of pathogenic strains of Salmonella enteritidis by ribotyping. J Clin Microbiol 1996; 34: 2294-2296. 